Introducing philosophical discussions to young people in secure accommodation

Claire Cassidy Gavin Heron

University of Strathclyde 


\section{Introducing Philosophical Discussions to Young People in Secure Accommodation}

This article focuses on a unique project designed to gauge the impact of using Philosophy with Children on young people in secure accommodation. This article describes the challenges and opportunities presented in introducing practical philosophy in such a setting. While the impact of the intervention on the young people's self-regulation is reported elsewhere (Heron \& Cassidy, 2018), the present article discusses the nature of the dialogue and the influence of the philosophical dialogue's structures on the young people's participation and their lived experiences.

\section{Secure Accommodation for Young People}

Internationally, secure accommodation (locked provision) for young people is amongst the most contentious and expensive provision in social work. Known variously as children's homes, juvenile detention centres, treatment centres and youth reformatories; the unifying aspect being that young people have lost their liberty, it is often seen as a 'last resort' when all other interventions have failed (SWSI, 1996). Removing such a basic human right arises from concern over offending behaviour and serious risks young people pose to themselves and/or others (Walker et al., 2006). Controversy surrounds the ethics of removing a child's liberty, ineffective decision making, the punitive nature of some institutions, impact on family members, the mixed composition of young people in one setting, and the effectiveness of interventions in changing behaviour (Roesch-Marsh, 2014; Sinclair \& Geraghty, 2008).

For young people deemed to be 'out of control' or 'beyond control', secure accommodation has a dual purpose of rehabilitation and protecting the public. The physical control of young people is perhaps the most obvious function of secure care. Smith (2005) suggests that this control is achieved through buildings' physical structures and the care provided, with Idsoe (2016) stressing the need to consider how students' affective well-being might be impacted upon by the ethos of the secure setting. Staff might gain insight into young people's perspectives through the controls that are in place, allowing specific behaviour and problems to be addressed. Interventions used in secure accommodation involve a variety of professionals and agencies and are considered in relation to the young person's family and wider community context. Yet, despite the emphasis on control, limited evidence exists to suggest secure accommodation is more effective than community-based alternatives such as children's homes or residential schools (Bullock, Little \& Millham, 1998; Walker et al., 2006). 
There is no single, preferred method of intervention within secure accommodation. The literature tends to focus on the need to create a positive living environment using, for example, prosocial modelling, behaviour modification, life space intervention and opportunity-led work (Decheneau, 2011; Smith, 2005). These approaches are not unique to secure accommodation, having been developed across a range of group living environments and residential care settings internationally. Young people in secure care are among the most damaged and vulnerable in society, many having experienced highly stressful and chaotic family circumstances, such as parental mental and physical illness, addiction, domestic violence, loss and bereavement (Mental Welfare Commission for Scotland, 2014). Secure accommodation residents tend to have one or more known additional support need, including social, emotional and behavioural difficulties, poor mental health, learning difficulties, and language and communication disorders. Additionally, studies consistently show that, prior to admission, young people exhibit a range of complex behaviour, including: absconding; misusing alcohol and illicit drugs; being manipulated by unsuitable people; involvement in highly disruptive behaviours; having unsafe sexual activity and being sexually exploited; self-harming; and offending (Bullock et al., 1998; Denecheau, 2011; Roesch-Marsh, 2014; SCRA, 2010). These issues can result in 'structural marginalisation' (Denecheau, 2011, p.278) where young people, experience difficulties that present further challenges when integrating into society.

Some of this behaviour and these problems continue in secure accommodation, while others are negated by the controlling environment. Intervention is not, however, merely about changing unwanted behaviour; its focus should be on supporting individuals' development (Maier, 1987). While it may be essential and appropriate to address specific behavioural problems, it is also plausible that an intervention can be effective irrespective of the reasons a young person enters secure accommodation. With the aim of offering an intervention that might prove engaging for young people, the education manager from the Centre where this study was conducted wanted to introduce the young people to Philosophy with Children.

\section{Philosophy with Children}

Evolving from Lipman's original Philosophy for Children programme in the United States (Gregory, Haynes \& Murris, 2017; Lipman, 2003; Lipman, Sharp \& Oscanyan, 1980; McCall, 2009), there is a range of approaches to Philosophy with Children. Essentially, it is a structured dialogue revolving around philosophical questions, usually generated by the participants. A facilitator maintains the dialogue by supporting its structure but does not contribute ideas to the dialogue herself. This study 
focuses on one specific Philosophy with Children practice - Community of Philosophical Inquiry (Cassidy, 2007; McCall, 2009).

Community of Philosophical Inquiry's structure remains the same, regardless of participants' age or ability. In short, participants sit in a circle to ensure they can be seen and heard by everyone in the group, with the facilitator situated outwith the circle. The sessions begin with the reading of a stimulus, usually a short text, for example, a poem, newspaper article or short story. Participants then ask questions prompted by the stimulus and the facilitator records these and chooses the question with the strongest philosophical potential for consideration (Cassidy, 2012). If participants wish to contribute to the dialogue they must first raise their hand and wait to be called. The facilitator selects the order in which participants speak as she juxtaposes participants' perspectives to drive the dialogue further philosophically. When contributing, participants begin by agreeing or disagreeing with at least one previous contribution and provide a reason for that dis/agreement. They may not refer to an authority such as a book, a teacher or an internet source as the reason for their dis/agreement; they should offer their own thinking, though not necessarily their own opinions. Technical language and jargon are not permitted; participants must use everyday language to make the dialogue as accessible as possible. The facilitator, aside from selecting speakers, intervenes to request clarification of points made. The overall aim is to inquire philosophically rather than to reach a consensus or conclusion as this would suggest that the question or problem has been resolved and that questioning or thinking on the topic may stop (Cassidy, 2007; Cassidy \& Christie, 2013; McCall, 2009).

Community of Philosophical Inquiry, and Philosophy with Children generally, is practised in a range of settings internationally, predominantly in schools. Considerable evidence exists that Philosophy with Children has positive effects for children of different ages. For example, Gorard, Siddiqui and See (2015) demonstrate how it has raised attainment, echoing findings from other studies, including Topping and Trickey's (2007a, 2007b), where cognitive gains were evidenced and maintained two years later. Further, evidence from their study shows benefits on the affective dimension in relation to participants' empathy and confidence (Trickey, 2008). Cassidy and Christie (2014) demonstrated that participants' reason-giving improved after only ten one-hour sessions of Community of Philosophical Inquiry. Similarly, Daniel (2008) and Daniel and Auriac (2011) show how Philosophy with Children develops critical thinking and higher order thinking skills, while Colom, GarcíaMoriyón, Magro and Marilla's (2014) longitudinal study of the impact of Philosophy with Children on children's cognitive and affective development offers positive initial results. It is in this context that 
Community of Philosophical Inquiry was thought to be a potentially positive intervention with young people in secure accommodation.

\section{Method}

Insight and understanding of participants' lived experiences can be gleaned from a case study approach (Bassey, 1999). Adopting this approach, researchers can situate their study in one institution to develop understanding of an issue that has not hitherto been investigated (Miles, Huberman \& Saldaña, 2013). As such, the present study offers a unique insight into the introduction and implementation of one intervention - Community of Philosophical Inquiry - with young people in a Scottish secure setting.

The Centre's education manager had heard a presentation on Philosophy with Children from one of the authors. Consequently, he invited the team to introduce Philosophy with Children to young people in the Centre, and for this to be researched. This article focuses on the following research questions:

1. To what extent can young people in secure accommodation engage with practical philosophy?

2. What are the challenges and opportunities in introducing practical philosophy to young people in secure accommodation?

The Centre employs a range of interventions aligned to the Getting it Right for Every Child (GIRFEC) (Scottish Government, 2008) agenda in Scotland, where a consistent and co-ordinated approach has been established for all children across the range of services provided. The Centre's interventions include: anger management; violence is not the only choice; drug and alcohol awareness; Assert Yourself; victim empathy; Girls Moving Forward; Cognitive Behavioural Therapy; anxiety prevention; sexual health education; and some alternative therapies such as reiki and reflexology. These interventions are mainly directed at the young people as individuals; little is done, either as part of the interventions or schoolwork generally, that is collaborative. The young people find themselves in small group settings, but do not often work as a group, a key element in the promotion of collaborative learning (Christie, Tolmie, Thurston, Howe and Topping, 2009). Staff saw the introduction of Community of Philosophical Inquiry as supplementary and complementary to what was already on offer, particularly in providing opportunities for collaborative working.

Participants 
Young people and staff working with them participated in the study. We met the young people in the informal setting of their home groups, during their lunch break, to introduce the idea of participating in philosophical discussions. We explained that doing philosophy meant working in a group to discuss ideas. After this initial introduction, the education manager recruited participants by extending an open invitation and asking young people to let him know if they wished to participate. All young people from the Centre were eligible to attend the sessions, and were able to decide for themselves if they wished to join the sessions or remain with their timetabled activities. No young people were deliberately excluded from participation, with the education manager ensuring that they knew that they were free to choose to attend the sessions if they wished, regardless of their timetable. Similarly, staff were also told about Community of Philosophical Inquiry and were invited to participate. The only bar to their participation was their timetable. As with the young people, they alerted the education manager if they wished to participate. We had no control over who did or could attend the sessions. All young people and staff who requested to participate were included in the sessions.

The young people were aged between thirteen and seventeen and did not necessarily belong to the same groups or classes during their time in the Centre. Four young people, all male, were consistent members of the sessions. A further seven male and four female participants joined the sessions less frequently. In all, five members of staff who worked closely with the young people participated in the study. However, it was later determined that it may be more helpful to the young people if staff did not participate in the sessions, so subsequent dialogues involved only the young people (for more detail, see Heron \& Cassidy, 2018). There was always at least one staff member observing the session, mainly in a supervisory capacity.

The sessions

The Community of Philosophical Inquiry sessions followed the structure outlined above. However, the first session demonstrated that using a written stimulus was not possible because of the participants' varied literacy levels and their unwillingness or inability to sit quietly to listen to the story being read. The facilitator, therefore, brought questions to stimulate the dialogues but the participants also offered questions, having sent these in advance or posing them at the start of the session. The facilitator's questions were not all used, but were available should the participants not generate any. It was anticipated that the facilitator's questions would be easily accessible to the participants, such as: Is it ever okay to break rules? What makes something art? Do footballers get paid too much money? and Should we have a royal family?. The facilitator chose the question, 
meaning sometimes she selected the question she had brought, and sometimes one of the participants'.

To fit around the young people's timetable and the other work commitments of the researchers, Community of Philosophical Inquiry sessions were scheduled for an hour, once a week for ten weeks. Participants sometimes had other commitments, such as attending court hearings, work experience and other classes, so maintaining a consistent group was at times problematic, though, as noted above, there were four consistent group members across the sessions.

One of the researchers facilitated the dialogues and another observed the sessions at a remove from the group. The dialogues were audio-recorded. The researchers met immediately following the dialogues to listen to the recordings and to make observational notes about the sessions.

Interviews

A semi-structured interview format was devised to elicit specific information whilst allowing interviewees to generate additional information they thought important. The interviews were audiorecorded and transcribed verbatim and a thematic analysis (Denscombe, 2010) was applied to identify themes emerging from interviewees' accounts of their experiences. The researchers did this independently in the first instance. They then came together to examine the emerging themes from the other's analysis, before focusing these through iterative discussions which also involved a third, independent colleague. This allowed for an interpretative approach (Miles et al., 2013).

Following the intervention, six young people and five key members of staff, were interviewed. Not all young people were available for interview because of their commitments or because they had left the Centre. Their commitments were external to the Centre such as court hearings or work experience. It was not possible to reschedule the interviews under these circumstances. It was also not possible to contact young people who had left the Centre as the Centre is bound by confidentiality not to release contact details of those no longer there. No participants in the project and who were potentially available declined the invitation to interview. Staff, in their interviews, though, made comments pertaining to specific young people, including those who were not interviewed, so some insight was afforded in this way. Interviews were audio-recorded and lasted approximately ten minutes with the young people, while staff spoke for between thirty minutes and an hour.

The interviews with young people were conducted in a one-to-one context by one researcher in a conversational manner. The interviews were open-ended, allowing the young people to say whatever they wished about their experiences of the dialogues. They were invited to say whether or 
not they had enjoyed the sessions, what they had enjoyed, or not, why they had come, whether anything had particularly interested or challenged them and what, if anything, they had taken from the sessions. They were also given the opportunity to discuss specific dialogues or anything else they wished to raise.

Staff interviews were more structured as there were key questions or issues the team wished to address. Staff spoke freely and at length. Like the young people, they were asked why they had attended the sessions and what they had found interesting or challenging. They were asked about how sessions differed to their normal interactions with the young people and how they saw the use of Community of Philosophical Inquiry rules in the dialogues being useful, or not. They were invited to speak about what they thought might be gained from introducing practical philosophy to young people in secure accommodation.

\section{Ethical issues}

As the young people participants in the study belong to what is considered a 'vulnerable group', the application for ethical approval was approved by the University Ethics Committee. Further, as the participants live in the Centre, the University's ethical procedures allow that a senior member of staff within the Centre acts as gatekeeper, in loco parentis, and can provide informed consent for the participants. All young people were fully informed of the project at the initial meeting when we presented the project. They were able to ask questions of us at this time, and were encouraged to contact us, through the education manager, if they had further queries about the project. No pressure was exerted upon young people to join or remain on the project. This was also the case for key staff who worked regularly with the young people and were invited to participate by the education manager. All participants provided informed consent. Participants' names have been changed to preserve anonymity. No incentives were offered for participation in the dialogues or the follow-up interviews. Indeed, this was discussed with the education manager who was clear that this would not be permitted should it have been requested.

\section{Findings}

The impact of the intervention was seen in three main areas: the dialogue itself; the structures involved in the Community of Philosophical Inquiry dialogues; and the lived experiences of the young people. Direct quotations have been used throughout this section as they are representative of the views offered and to allow the young people to have their own, often marginalised, voices heard in the research (Lewis, 2010).

Dialogue 
The young people's questions included, but were not limited to: Why did terrorists attack Paris? What's wrong with swearing? Are there parallel universes? Is there a God? Should all people be paid the same? Who invented sex? Why do people keep on asking me things? Is evolution a lie? Should you respect other people? Is there an afterlife? What came first, the chicken or the egg? and Should 'life' mean life? It is clear that some of the questions, such as 'Who invented sex?' were not overtly philosophical. The young people were enthusiastic about the questions, even ones that they had not asked. They were eager to discuss questions relating to evolution and those pertaining to their immediate lives such as the invention of swearing or consequences of committing certain crimes. What became clear, though, was that they struggled to generate particularly strong dialogues around the topics where their personal experiences were more obviously evident. Content of the dialogues went from one extreme, such as sex was invented by 'cavemen who were bored and experimented with their stones' (Tony), or 'It could have accidentally happened, they could have tripped and thought that feels alright...' (Derek) to the overtly philosophical in dialogues on the nature of art or personal identity.

The dialogue was much stronger philosophically when the participants explored more abstract ideas, as in the following example where five participants were present and discussed one of their own questions situated in philosophy related to metaphysics: Is there an afterlife? Note that the facilitator called on the participants to speak but this has been redacted due to word limit constraints; only direct questions from the facilitator have been included. The extract from a dialogue involving the young people is shared to illustrate the philosophical nature of the dialogue, the young people's engagement with the ideas and with one another, and to illustrate the development of the dialogue through the interactions and connections made by them. 
Jeff: I think about this all the time, what if you wake up one day and you're still a baby lying in your bed? How annoying would that be? When you die, you don't actually die, you wake up and you're still a baby. It just happens over and over and over again.

Tony: I agree with everybody again, but listen to this, you've got to listen to this. See what Jeff was saying there about the dead thing, that you die and you wake up, I agree with that, but see when you wake up as a child, how do you know you've just died?

Jahir: You don't, mate.

Tony: You don't. So, see when you were born, how do you know you didn't just die instead of coming out a 'thing'? [gestures to suggest a vagina]

Jeff: I disagree with what Jahir and Derek were saying. I wasn't talking about reincarnation. I'm talking about when... say your grandad died; your grandad, what if he's not really dead? What if you're just dreaming? You are a baby right now, you are a baby and you are just dreaming. You're not being reincarnated, you're just dreaming. When you're actually in a dream it doesn't feel like... say you've been asleep for twelve hours, it doesn't feel like twelve hours, it feels like three days. A dream can go on and in the dream you've been sleeping for three days.

Jahir: I disagree with Jeff because if that's me dreaming, so that means my granda's not real, that means you're not real, because now l'm dreaming. But you obviously know that you're real because you think you're dreaming as well. You're living in a dream right now, mate.

Facilitator: He thinks he's real because he's dreaming?

Jahir: No, no. Obviously I know he's real; I know this isn't a dream now.

Facilitator: How do you know that?

Jahir: How do I know that? Because it's a fact. Well, it's not a fact because it's not got anything to back it up. Because I can feel, I can feel pain and all that. If this was a dream I could've controlled it. Obviously you can control your life to an extent, but if l'd done something wrong and I'm here [in the Centre] now, if that was the case [that it wasn't real] I could've just flown away or something into space and not let anybody catch me. That means one dream.

Jeff: What you said about the one dream, I agree with you to a certain extent, you can feel in a dream. Like Derek said, you've got your senses in a dream, but it's been proven, well, I'm not sure if it's been proven, but there's reports; like say I was in a dream with Jahir and they've got some sort of link, it might be possible that we're all in the one dream. It's just that Derek is two [years old] and I'm one [year old] and he's been in the dream longer than me, that's why he's older than me.

Facilitator: Jim, whose dream is this if we're all in the one dream?

Jeff: It's nobody's. It's like The Matrix, you get plugged into a computer, it's like a server and everybody plugs in and when you fall asleep you go back to normal life. So at night, when you go to bed, you go back to normal time. I disagree, too, right, because you do get dreams, I get dreams, like say Tony's in that dream and it's like Tony is in that dream because he speaks like Tony would speak and he's acting how Tony would act. So, when we go to sleep, we're just going back to the normal world and when this [indicating the room], when we wake up we're actually dreaming and it's like a server that everybody goes into when they're sleeping.

Jahir: So we're all dreaming the same dream at the same time?

Jeff: Aye. Well, it's like the computer, we all go onto the same server, then when you log off that's you going back into real life. This isn't real but you can't remember in the dream what real life is like.

The extract demonstrates participants' ability to engage in philosophical dialogue. Discussing the fundamental question of knowing whether one is awake or dreaming they offer a thought experiment and reference to the film The Matrix as a way of explaining and exploring their ideas. 
With minimal intervention from the facilitator, they work together to generate the dialogue and raise key philosophical ideas pertaining to questions of existence and reality.

The extract also shows that the participants waited to be invited to speak. Some were more patient than others, as in any group of Community of Philosophical Inquiry participants. Pete and Dave spoke in their interviews about liking the calm of the dialogues and that they thought they were more patient than at the beginning of the intervention, both in the sessions and in other aspects of their lives. It was clear in the manner of the dis/agreements that the participants listened attentively in the dialogues, as illustrated when one participant delighted in highlighting to another that he had just contradicted himself, while another joked that one of the other participants said he had not finished speaking but that he kept inserting full stops when he speaks. On several occasions, some participants sat silently and did not contribute until much further into the session, such as Tracy in week four, who was silent for the first thirty minutes but when she spoke demonstrated that she had been listening to previous contributions. Participants made extended contributions and connections between the views they presented and those of others, as illustrated in the transcript. With each dis/agreement they offered reasons for their dis/agreement. There were also instances when they partially dis/agreed with contributions.

Stronger philosophical dialogues had more momentum in terms of the ideas being introduced and explored; the participants were more engaged, being caught up in the sessions in such a way that they remained focused and excited. Laughter was a big feature in the sessions, prompted by the examples that were used or when the young people became confused in making their point, such as Jahir in the dialogue above when he emphasised 'I'm very disagreeing' or Pete who said 'Hold on while I phone my pal' when he became stuck. Participants' enthusiasm went beyond the sessions, with staff reporting that some continued to talk about the topic immediately after the session. Notably, the Cognitive Behavioural Therapist commented that the young people often spoke in her sessions about the dialogues. In their interviews, the young people also said they sometimes talked with other staff about them.

Community of Philosophical Inquiry structure

Initially, participants struggled with waiting to be called to speak, following the agree/disagree format, and the need to provide justifications for their dis/agreements, with Dave complaining at one point that sticking to the rules was 'a pain in the bum' and in his interview saying that 'sticking to the rules was hard'. One participant in the first week was frustrated by the rules, removing himself from the circle. However, he clearly wanted to engage and struggled with the urge to 
participate while also remaining at a distance, eventually contributing from outside the circle and following the Community of Philosophical Inquiry structure. By week four, the young people had grasped the structure and were able to wait until they were called to make their point. Pete acknowledged in his interview that this helped, sayingthat he liked 'getting your point of view across and you don't have to shout over everybody'. Staff member Laura said that the young people would normally find it difficult to sit in the one place for any length of time and listen to one another; she was surprised that they could do this during the sessions. The young people's ability to follow the structure can also be seen in the extract above. Indeed, the core group modelled the structure for new participants and, on occasion, ensured their peers did likewise, pre-empting the facilitator by asking 'Who do you agree with?' when this had been omitted, or when Tam was new to the group and started speaking, Dave gently stopped him, saying, 'No, do you agree or disagree?', or when Ann referred to 'astral projection' and Dave complained she was using technical words. One member of staff observed that 'I was just fascinated by how well the young people bought into it, how well they were able to follow the rules, they were able to stay silent and really actively listen to the points of view of other young people' (Keith). He went on to say 'what shone through was that there was control in the sessions without having to challenge that behaviour [swearing]', suggesting 'it was almost as if it will be challenged in a different way' (Keith).

Not all participants liked one another as they discussed peers while waiting for others to arrive at the sessions. However, any dislike was not evidenced in the dialogues as they were able to agree with points made by those they disliked. Similarly, friends were able to disagree with one another. The participants even tried to draw others into the dialogue, for example, when Tony says, 'Derek, you've not said anything yet, brother, come on'. The young people could be empathetic, with one participant encouraging another who was struggling to make her point, prompting, 'Come on, Ann'.

The sessions were enhanced by humour which featured heavily, with Ann saying she attended the sessions because they were 'funny, a good laugh'. Participants often made jokes, and some of the examples used to illustrate points were humorous or participants would joke about one another's or their own - difficulty in articulating their thinking, such as when Pete said he was 'going to do a Dave', meaning he would contribute in Dave's regular style.

The young people's lived experiences

Participants were told prior to the project that philosophy was about argument and discussing ideas. Those interviewed said they initially came to the sessions because they liked arguing. On one week, as the group were entering the classroom, one young person (Tony) said he loved arguing and a 
member of the accompanying staff 'corrected' him to say that they were not there to argue, but to have a discussion. Another young person (Jahir) disagreed with her and said that it was an argument and that this was acceptable if they provided a reason for what they said. The participants looked to the facilitator for approval and were pleased to have their assertions confirmed.

Participants often displayed weak general knowledge during the dialogues. The ways in which information was used, or was not able to be used, in sessions was marked. Biological concepts such as those used when discussing reproduction were not present for the group. There was much misinformation and even a lack of knowledge about terminology for body parts. In the dialogue on Why did terrorists attack Paris? only one participant, Tam, seemed to have watched enough news to understand some of the background that might have provoked the attack. Jim, who asked the question, was unable to start the dialogue because he said he didn't know and that was why he had asked the question. Similarly, in talking about What makes something art?, though philosophically an interesting dialogue, participants struggled to talk about specific artists to exemplify a point, with Jim saying he'd never seen the Mona Lisa and Jahir confusing Da Vinci and Van Gogh when he said 'that Leonardo Da Vinci, he cut his ear off for art', or in another session when discussing space, some participants did not have the simplest grasp of the topic that might be expected from children in primary school. The confusion in piecing together bits of information or the lack of general knowledge was often a feature, which in some ways stunted the development of the dialogue.

Interestingly, the dialogues that focused on abstract ideas such as art or metaphysics were more overtly philosophical. In discussing What's wrong with swearing? participants could not move from suggesting that one should not swear in front of parents because this demonstrates a lack of respect. Despite the facilitator probing why this might be the case, they could not take the dialogue further. The dialogue on Who invented swearing? lasted around three minutes, while others, such as What makes something art? lasted twenty. Similarly, when the question Should 'life' mean life [in relation to prison sentences for serious crimes]? was chosen, the dialogue did not shift from the very concrete experiences participants had. They found it hard to move away from personal experiences and were puzzled that the facilitator asked questions that demanded they go beyond this, such as when Jim was asked the difference between a swear-word and any other disrespectful word; they knew what might count as disrespectful but struggled when pushed to explain the concept.

The participants' lack of vocabulary was a feature of the sessions, with them often experiencing difficulty in articulating what they meant. However, one member of staff (Keith) commented that he was surprised by some of their vocabulary and how they were able to explain what they meant 
because he didn't think they had the capacity. All participants responded positively when pushed by the facilitator to explain further or to illustrate a point, as can be seen in the extract above.

Expectations of the young people's abilities were interesting. Staff commented that they were surprised by the dialogues they had witnessed, the manner in which the young people engaged, and the positive impact it had on the participants generally. Keith suggested that it was 'stunning' to see how the dialogue unfolded and that there was evidence of real thought. He went on to speak about those who generally would not be able to work in the kind of forum presented and that this had impacted upon the young people's care plans. He gave an example of one young person (Derek) whose behaviour in classes caused serious concerns and who would never have been chosen to represent his peers on the pupil council, adding that he had been surprised that he had joined the sessions, noting that attending the sessions was 'a huge turning point for him and he was devastated when they came to a close'. Derek subsequently looked for projects to become involved in. The staff member, Keith, said that prior to the sessions Derek's emotions made him somewhat incoherent when speaking but that his confidence in articulating his thoughts, after the philosophy sessions, had aided his reflections on who he is. The Cognitive Behavioural Therapist emphasised this point too, saying that the boost to the participants' self-esteem from people listening to their opinions was significant because, though desirable, it does not happen often enough for the young people in the Centre.

The young people, in their interviews, commented that people do not expect those 'in secure to be able to talk about ideas like that' (Pete). Indeed, they said that they surprised themselves. Pete spoke about being impressed by Carla's questions, saying that 'Carla's questions were unbelievable. You'd think that people in secure didn't have the ability to come out with questions like that...Most didn't go to education when they were out [of secure], so you'd think they were NEDs - noneducated delinquents - but they're not'. Dave said that participating in Community of Philosophical Inquiry had helped him to speak out more and that he was a better speaker.

When the sessions ended, some participants sought other outlets to engage in discussion and, for example, one volunteered to represent his peers on one of the Centre's committees. Others also saw Community of Philosophical Inquiry as part of what they enjoyed doing, with the young people, including some who had never previously participated, asking to attend sessions during their school holidays.

\section{Discussion}


In acknowledging the likelihood that those in secure accommodation will have had problematic and often chaotic lives (Bullock et al., 1998; Roesch-Marsh, 2014; SCRA, 2010), the need for control through the types of care and structure offered to the participants (Cobbett, 2016; Smith, 2005) can be seen to have had an impact. Community of Philosophical Inquiry's structure offers control because participants had to follow the rules. However, the structure can also be seen as liberating; they chose to follow the rules to make sessions work for themselves and to direct the dialogue where they chose. This can be seen in the extract when they introduce their own thought experiment and go on to explore whether they are, or might know if, they are awake or dreaming.

While it seems counter-intuitive to offer potentially volatile young people opportunities to argue, the study shows that they not only enjoyed it, but that the 'I agree/disagree with... because...' structure supported them in arguing without conflict (Heron \& Cassidy, 2018). This is evident on several occasions in the extract, not least when James says to Jahir, 'I agree with you to a certain extent'. Here, he demonstrates his ability to disagree calmly and coherently, showing where there is common ground but leading to where there is disagreement. Importantly, participants understood that their arguments demanded justifications. They not only justify their agreements/disagreements, they also justify the points they introduce such as James explaining how one experiences dreams as extended periods of time, and in the exchange with the staff member who asserted that the young people were to have discussion, not argument. The requirement to provide justifications allows participants to make connections and practise their reasoning (McCall, 2009).

Those in secure settings are likely to have disrupted or limited experiences of formal education. The lack of general knowledge evidenced by the young people in this study was concerning, having implications for their lives beyond the Centre. The dialogues, such as those relating to evolution, procreation and politics evidenced this lack of general knowledge and stunted the dialogues somewhat as participants became confused or did not have enough background information to draw upon. The more philosophical dialogues seemed to work because more open questions were addressed that the participants had not previously explored. By being able to work collaboratively in Community of Philosophical Inquiry suggests that opportunities exist in such settings for collaborative groupwork to be used that might build upon the topics explored in philosophical dialogue or as an introduction to topics. Teachers, as Christie et al. (2009) suggest, should plan for collaborative working by building collaboration into tasks; Community of Philosophical Inquiry does this. Due to small class sizes in the secure context, young people could undertake collaborative projects while still working at their own academic levels, with Community of Philosophical Inquiry 
acting as a key element within the delivery and assessment of the planned activities. Cassidy, Marwick, Deeney and McLean's (2017) study suggests that some teachers might find this approach useful in assessing learning when traditional written assessments are overly challenging for learners.

Given that all staff in their interviews noted their surprise on hearing the young people's views or the ways in which they think, questions arise around expectations that staff have of the young people and how they generally engage in class activities. Community of Philosophical Inquiry's structure facilitated participants' engagement and the content of the dialogues. It offers a model that might usefully be employed elsewhere in the curriculum and in the teachers' pedagogy. In light of the questions the young people asked, there are several opportunities for collaborative, integrated, cross-curricular approaches to learning that might usefully be stimulated and supported by Community of Philosophical Inquiry. The activities themselves could prompt further philosophical dialogues. In doing so, Community of Philosophical Inquiry would be integral to the practices of the setting, with young people recognising opportunities to influence and shape their learning. This, in turn, could motivate them in their learning, broaden their horizons, support their vocabulary, provide opportunities to extend their general knowledge and offer areas of interest to be pursued independently, while potentially also strengthening important staff/young people relationships (Denecheau, 2011). Additionally, Community of Philosophical Inquiry provides opportunities to acquire and practise skills that will be useful to the young people on leaving the Centre; for example, they learn to listen carefully, explore different perspectives and support others in developing their views while questioning their own and others' ideas in order to build new ones (Gregory, 2008).

Given the generally low expectations for those in secure accommodation (Decheneau, 2011), including on the part of the young people themselves, the participants' engagement with the philosophical dialogue was often impressive. The excerpt above demonstrates their engagement with the topic, while also illustrating their confusion as they grapple with the challenging ideas they themselves introduce. None of the participants had read any philosophy, yet they introduced a thought experiment, communicated it to their peers, used examples, posed problems, listened to others' perspectives, offered their own, and engaged in topics that have long-puzzled academic philosophers. Being confident enough to articulate their confusion amongst peers with whom they often had difficult relationships suggests trust and resilience on the part of the young people and a sense that a Community of Philosophical Inquiry had been created and might be built upon in other aspects of their lives in the Centre.

In common with other Community of Philosophical Inquiry groups, the participants successfully came to regulate their own behaviour in the sessions, and also, on occasion, that of their peers 
(Cassidy, Christie, Marwick, Deeney, McLean \& Rogers, 2017b; Heron \& Cassidy, 2018). A shift in power from adult to young people often results in enhanced self-regulation (Zimmerman, 2008), and Community of Philosophical Inquiry allowed for this to happen, with the facilitator following the participants' lead in the dialogues. Power is a significant factor for those with social, emotional and/or behavioural difficulties (Cobbett, 2016), so this shift was important. Indeed, over the course of the intervention, the well-practised members of the group modelled the appropriate behaviour for novice participants, reinforcing the positive behaviour the novices could see working for the others (Cassidy et al., 2017b). The participants came to recognise that certain structures were actually beneficial to them and that not all rules are limiting; as also seen in Cassidy et al (2017a) and Cassidy et al's (2017b) study with children with emotional and behavioural difficulties. In waiting to speak, participants saw that others listened to them, and in using the agree/disagree format they easily made connections with their peers as a way into the dialogue and in order to develop the inquiry. It was, in other words, a safe space for them to air their views.

Worth noting, too, is that the facilitator never validates or comments on contributions made; participants do not receive praise, encouragement or disapproval for their contributions, all contributions are treated in the same manner. This is not usual practice in working with children generally, but particularly those who may be considered vulnerable or with particular learning needs (Cassidy et al., 2017a; Cassidy et al., 2017b). It may be that the facilitator's neutrality encouraged participants to contribute and follow the rules, enabling them to take responsibility for the content and direction of the dialogues. Cassidy et al. (2017b) support this, explaining that some children with emotional and behavioural difficulties benefit from feedback that comes from their peers' engagement with their contributions. Encouraging young people to take more control over arguing might prevent them from losing their temper and promote engagement and enjoyment.

Given the challenges of engaging with philosophical ideas generally, but even more so for those with limited vocabulary, the form of control offered by Community of Philosophical Inquiry may be liberating, while other behavioural controls, such as a ban on swearing, might squash some opportunities for young people to express themselves. Perhaps some of the very explicit and externally imposed controls on young people in secure accommodation may be more limiting in terms of supporting them to establish behaviour that enables collaborative working, self-expression, creativity, and engagement with others and ideas beyond their immediate lived experiences.

\section{Limitations}


The main limitations in the study pertained to the nature of the setting in which the study was conducted. It was not possible to guarantee a consistent group because of the transient nature of the population, or due to participants' external commitments, or because they chose not to attend a session. Similarly, interviews were not possible with all those who had participated in the sessions due to them having left the Centre or having commitments outwith the Centre.

\section{Conclusions}

For those with limited life chances, effective interventions need to be introduced early, otherwise they are 'more likely than the general population to develop mental health conditions, fail in education, develop drug addictions, become criminally active/antisocial and become parents of similar children who go on to repeat the cycle' (Cobbett, 2016, p.404). Introducing Community of Philosophical Inquiry in a secure setting suggests that some forms of control may be a liberating factor for young people. The structure allows participants freedom to express their ideas, engage collaboratively with one another, and self-regulate their behaviour. Positive expectations from staff will have a bearing on young people's progress (Denecheau, 2011), as do their interactions (KaimeAtterhög, Persson \& Ahlberg, 2017), so it is vital that staff are positive and engaged in advancing interventions that may initially seem unusual or innovative. Indeed, in this study, it seems that providing the opportunity to argue in a controlled and reasoning manner was the hook to the young people's engagement.

Irrespective of the context or the types of secure accommodation used around the world, this study suggests that by offering young people opportunities to be in control of their dialogues, to set their agenda while following a clear set of rules, they can come to respect that some rules are necessary to advance their engagement and enjoyment of particular activities. Further investigation is warranted to gauge the impact of a Community of Philosophical Inquiry intervention with those in secure accommodation in terms of its transferability beyond the confines of the sessions themselves, as undertaken in studies in mainstream contexts (Cassidy \& Christie, 2014; Cassidy et al., 2017b). In allowing young people more control in directing their learning, positive outcomes for their present and future lives might be supported. As Cassidy et al. (2017a) conclude in their study with marginalised children, the likes of Community of Philosophical Inquiry rather than a traditional, behaviourist approach where children are rewarded or punished, is more inclusive. Community of Philosophical Inquiry, therefore, may have something to offer those living and working in secure accommodation by supporting them while within the secure setting and as they transition into the wider world. 


\section{Research ethics}

Ethical approval for this project was given by the University of Strathclyde's Ethics Committee, Glasgow, Scotland.

\section{Funding}

This research received no specific grant from any funding agency in the public, commercial, or notfor-profit sectors.

\section{Acknowledgements}

The authors would like to thank Prof. Emeritus Donald Christie for his support with this project. We would also like to thank the anonymous reviewers for their time, consideration and helpful comments.

\section{References}

Bassey, M. (1999). Case Study Research in Educational Settings. London, UK: Open University Press.

Bullock R., Little M., \& Millham S (1998). Secure Treatment Outcomes: The Care Careers of Very Difficult Adolescents. Aldershot, UK: Ashgate.

Cassidy, C. (2007). Thinking Children. London, UK: Continuum.

Cassidy, C. (2012). Questioning Children. Thinking: the Journal of Philosophy for Children 20 (1\&2), $62-68$.

Cassidy, C., \& Christie, D. (2013). Philosophy with Children: talking, thinking and learning together. Early Child Development and Care 183(8), 1072-1083. DOI: 10.1080/03004430.2013.773509.

Cassidy, C., \& Christie, D. (2014). Community of Philosophical Inquiry: citizenship in the classroom. Childhood \& Philosophy 10(19), 33-54. Retrieved from http://www.epublicacoes.uerj.br/index.php/childhood/article/view/20690/15016 
Cassidy, C., Christie, D., Marwick, H., Deeney, L., McLean, G., \& Rogers, K. (2017). Fostering citizenship in marginalised children through participation in Community of Philosophical Inquiry. Education, Citizenship and Social Justice 13(2), 120-132. DOI: 10.1177/1746197917700151.

Cassidy, C., Marwick, H., Deeney, L., \& McLean, G. (2017). Philosophy with Children, self-regulation and engaged participation for children with emotional-behavioural and social communication difficulties. Emotional and Behavioural Difficulties 23(1), 81-96. DOI: org/10.1080/13632752.2017.1388654

Christie D., Tolmie A., Thurston A., Howe, C., \& Topping, K.J. (2009). Supporting group work in Scottish primary classrooms: improving the quality of collaborative dialogue. Cambridge Journal of Education 39 (1): 141-156. DOI: org/10.1080/03057640802702000

Cobbett, S. (2016). Reaching the hard to reach: quantitative and qualitative evaluation of schoolbased arts therapies with young people with social, emotional and behavioural difficulties. Emotional and Behavioural Difficulties 21(4), 403-415. DOI: org/10.1080/13632752.2016.1215119

Colom, R., García Moriyón, F., Magro, C., \& Morilla, E. (2014). The Long-term Impact of Philosophy for Children: A Longitudinal Study (Preliminary Results). Analytic Teaching and Philosophical Praxis 35(1), 50-56. Retrieved from http://journal.viterbo.edu/index.php/atpp/article/view/1129

Cooper, P., \& Cefai, C. (2013). Understanding and Supporting Students with Social, Emotional and Behavioural Difficulties: A Practical Guide for Staff in Schools. Malta: European Centre for Educational Resilience and Socio-Emotional Health, University of Malta. Retrieved from https://www.um.edu.mt/_data/assets/pdf_file/0009/178650/Revised_Monograph_22nd_March.p df

Daniel, M-F. (2008). Learning to philosophize: positive impacts and conditions for implementation. A synthesis of 10 years of research (1995 - 2005). Thinking. The Journal of Philosophy for Children 18(4), 36-48.

Daniel, M-F., \& Auriac, D. (2011). Philosophy, Critical Thinking and Philosophy for Children. Educational Philosophy and Theory, 43(5), 415-435. DOI: org/10.1111/j.1469-5812.2008.00483.x 
Denecheau, B. (2011). Children in residential care and school engagement or school 'dropout': what makes the difference in terms of policies and practices in England and France? Emotional and Behavioural Difficulties 16(3), 277-287. DOI: org/10.1080/13632752.2011.595093

Denscombe, M. (2010). The Good Research Guide: For Small-scale Social Research Projects, $4^{\text {th }}$ Edition. Berkshire, UK: McGraw-Hill.

Gregory, M. (2008). Philosophy in Schools: Ideals, Challenges and Opportunities. Critical \& Creative Thinking 16(1), 5-22.

Gregory, M.R., Haynes, J., \& Murris, K. (2017). Philosophy for Children: an educational and philosophical movement. In M.R. Gregory, J. Haynes and K. Murris (Eds.), The Routledge International Handbook of Philosophy for Children (pp.xxi-xxxi). New York, USA: Routledge.

Gorard, S. Siddiqui, N., \& See, B.H. (2015). Philosophy with Children Evaluation and Executive Summary. London, UK: Education Endowment Fund. Retrieved from https://v1.educationendowmentfoundation.org.uk/uploads/pdf/Philosophy_for_Children.pdf Heron, G., \& CASSIDY, C. (2018). Using practical philosophy to enhance the self-regulation of children in secure accommodation. Emotional and Behavioural Difficulties 23(3), 254-269. DOI: org/10.1080/13632752.2018.1461469 Idsoe, E.M.C. (2016). The importance of social learning environment factors for affective well-being among students. Emotional and Behavioural Difficulties (21)2, 155-166. DOI:

org/10.1080/13632752.2015.1053695

Lewis, A. (2010). Silence in the Context of 'Child Voice'. Children \& Society (24)1, 14-23. doi: 10.1111/j.1099-0860.2008.00200.x.

Lipman, M. (2003). Thinking in Education (2 ${ }^{\text {nd }}$ edition). Cambridge: Cambridge University Press.

Lipman, M., Sharp, A. M., \& Oscanyan, F. S. (1980). Philosophy in the Classroom. Philadelphia, USA: Temple University Press.

McCall, C. (1991). Stevenson Lectures on Citizenship. Glasgow, UK: Glasgow University Press. 
McCall, C. (2009). Transforming Thinking: Philosophical Inquiry in the Primary and Secondary Classroom. London, UK: Routledge.

Maier, H. W. (1987). Developmental Group Care of Children and Youth: Concepts and Practice. New York, USA: Haworth.

Mental Welfare Commission for Scotland. (2014). Visit and Monitoring Report. Visits to Children in Secure Care Settings. Edinburgh: Mental Welfare Commission for Scotland. Retrieved from https://www.mwcscot.org.uk/media/203241/visits_to_young_people_in_secure_care_settings_fina I.pdf

Miles, M.B., Huberman, A.M., \& Saldaña, J. (2013). Qualitative Data Analysis: A Methods Sourcebook $3^{\text {rd }}$ Edition. London, UK: Sage.

Roesch-Marsh, A. (2014). 'Out of Control': Making Sense of the Behaviour of YOUNG PEOPLE Referred to Secure Accommodation, British Journal of Social Work, 44(2), 197-213. DOI: org/10.1093/bjsw/bcs102

Scottish Children's Reporter Administration (2010). Secure Authorisation in Scotland's Children's Hearing System: An Exploration of Decision Making, Placements, Outcomes and Social Backgrounds. Stirling, UK: Scottish Children's Reporter.

Scottish Government. (2008). Getting it Right for Every Child. Edinburgh, UK: Scottish Government.

Sinclair, R., \& Geraghty, T. (2008). A Review of the Use of Secure Accommodation in Northern Ireland. London, UK: National Children's Bureau.

Smith, M. (Editor) (2005). Secure in the Knowledge: Perspectives on Practice in Secure Accommodation. Glasgow, UK: Scottish Institute for Residential Child Care, Glasgow School of Social Work, Universities of Strathclyde and Glasgow. Retrieved from https://www.celcis.org/files/2314/3878/4209/secure-in-the-knowledge-perspectives.pdf

Social Work Services Inspectorate (1996). A Secure Remedy: A Review of the Role, Availability and Quality of Secure Accommodation for Children in Scotland. Edinburgh, UK: HMSO. 
Topping, K. J., \& Trickey, S. (2007a). Collaborative philosophical enquiry for school children: Cognitive effects at 10-12 years. British Journal of Educational Psychology 77, 271-288. DOI:

10.1348/000709906X105328

Topping, K.J., \& Trickey, S. (2007b). Collaborative philosophical inquiry for schoolchildren: Cognitive gains at 2-year follow-up. British Journal of Educational Psychology 77, 787-796. DOI:

10.1348/000709907X193032

Trickey, S. (2008). 'More than cognitive': reflections on the components of the

Clackmannanshire Thinking Project. Critical \& Creative Thinking 16(1), 23-43.

Walker M., Barclay A., Hunter L., Kendrick A., Malloch, M., Hill, M., \& Mclvor, G. (2006). Secure Accommodation in Scotland: Its Role and Relationship with 'Alternative' Services. Edinburgh, UK: Scottish Executive.

Wanjiku Kaime-Atterhög, W., Persson, L- A., \& Ahlberg, B.M. (2017). "With an open heart we receive the children": Caregivers' strategies for reaching and caring for street children in Kenya. Journal of Social Work 17(5) 579-598. DOI: org/10.1177/1468017316651989

Zimmerman, B. (2008). Investigating Self-regulation and Motivation: Historical Background, Methodological Developments, and Future Prospects. American Educational Research Journal 45: 166-183. DOI: org/10.3102/0002831207312909 